\title{
A matemática na área Ciências Agrárias: Contextos e conteúdos
}

\section{Mathematics and the area of agrarian sciences: Contexts and vontents}

\author{
PEREIRA, Luciana B.C. ${ }^{1}$ \\ SANTOS JUNIOR, Guataçara dos ${ }^{2}$ \\ OLIVEIRA, Lucas S. ${ }^{3}$

\section{Resumo} \\ Este artigo tem por objetivo apresentar os resultados de uma pesquisa que buscou mapear conteúdos \\ matemáticos que possam ser contextualizados em cursos superiores da área Ciências Agrárias. A coleta \\ de dados se deu por meio de um questionário que foi aplicado aos professores dos quadros efetivo e \\ substituto. Após a análise dos dados, os resultados apontam que os conteúdos mais citados pelos \\ professores pesquisados foram: Regra de Três, Porcentagem, Equações, Unidades de Medidas, cálculos \\ de área e volume. \\ Palavras-chave: ensino de matemática, ciências agrárias, interdisciplinaridade
}

\begin{abstract}
This article aims to present the results of a research that sought to map mathematical content that can be contextualized in higher education courses in the field of Agrarian Sciences. Data collection took place through a questionnaire that was applied to teachers in the effective and substitute staff. After analyzing the data, the results show that the contents most cited by the surveyed teachers were: Rule of Three, Percebtage, Equations, Units of Measure, area an volume calculations.

Keywords: teaching of mathematics, agricultural sciences, interdisciplinarity
\end{abstract}

\section{Introdução}

A Matemática está inserida nas mais diversas áreas do conhecimento humano e se faz presente nas atividades diárias, mesmo que não se perceba. Assim, os conteúdos da Matemática nos revela um celeiro de aplicações práticas, inclusive nas Ciências Agrárias, com suas variadas aplicações em atividades básicas do campo, pecuária, florestas e no desenvolvimento de pesquisas.

A busca por aplicações e contextos de cada área é uma atitude que deve partir dos professores ao se depararem com as áreas de atuação. Há áreas que é possível encontrar aplicações com mais facilidade por haver vários

\footnotetext{
${ }^{1}$ Universidade Tecnológica Federal do Paraná. Brasil. lucianapereira@utfpr.edu.br

2 Universidade Tecnológica Federal do Paraná. Brasil. Guata@utfpr.edu.br

${ }_{3}^{3}$ Universidade Tecnológica Federal do Paraná. Brasil. lukas201190@hotmail.com
} 
materiais publicados, outras com escassez de materiais exige além da busca de aplicações, um estudo dos conceitos pertinentes dessa área.

A contextualização pode ser vista como pressuposto de uma metodologia de ensino. A utilização desta metodologia precisa ser utilizada no sentido intencional e permanente, vinculado ao viver em sociedade do aluno na sua área de formação profissional.

Ensinar de modo contextualizado exige muito cuidado, pois, os contextos devem fazer sentido para os estudantes e ainda proporcionarem um conhecimento interdisciplinar. Não é aconselhável apresentar exemplos contextualizados de áreas distantes daquela em que os alunos estão se profissionalizando ou ainda apresentar contextos desconectados da realidade.

Outra situação relevante que pode ser considerado é o fato de alguns estudantes constantemente questionarem seus professores com a famosa pergunta "para que serve?" ou ainda " em que vou usar?" . O ensino de forma contextualizado é uma estratégia que pode ser motivadora e ao mesmo tempo resposta para esses questionamentos.

Diante disso, este artigo tem como objetivo apresentar os resultados de uma pesquisa que buscou mapear conteúdos matemáticos que possam ser contextualizados em cursos superiores da área Ciências Agrárias.

\section{Metodologia}

O local de realização da pesquisa foi a Universidade Tecnológica Federal do Paraná - Câmpus Dois Vizinhos Paraná - Brasil. O instrumento de coleta de dados foi um questionário que objetivou levantar dadaos sobre aplicações dos conteúdos de matemática nas disicplinas. Esse questionário foi aplicado à 80 (oitenta) professores (permanentes ou colaboradores) que ministram aula nos cursos de graduação em Agronomia, Engenharia Florestal e Zootecnia. Na análise dos resultados estes professores serão denominados P01, P02, P03... P80.

A pesquisa classificada como qualitativa e aplicada, foi marcada pelo propósito fundamental de promover o diálogo entre disciplinas, professores e conceitos. Para uma melhor análise, os resultados e discussões foram divididos em três categorias de análise: Disciplinas que utilizam Matemática; Conteúdos Matemáticos; e Assuntos contextualizados.

De posse das respostas dos questionários foi possível utilizar uma metodologia de análise de informações de natureza qualitativa, denominada Análise de Conteúdo, que tem seu foco em mensagens e categorias com o objetivo de manipular mensagens para confirmar os indicadores que permitam realizar inferências (BARDIN, 2016).

Contudo, também cabe destacar que o projeto que norteou esta pesquisa foi submetido à apreciação do Comitê de Ética em pesquisa da UTFPR, sob registro CAAE: 57081916.6.0000.5547, com parecer número: 1.675.433.

\section{Revisão de literartura}

Este estudo se originou devido a escassez de materiais didáticos, no idioma português, que dão suporte aos anseios de professores que buscam promover a aprendizagem com o auxílio da contextualização. Foram encontrados cinco livros, cujo foco é aplicações de Matemática na área Ciências Agrárias. Dois deles produzido exclusivamente no Brasil, um traduzido e duas publicações internacionais. Na sequência será apresentado uma breve análise de cada um deles com destaque aos conteúdos que abordam e aos objetivos propostos. 
O livro intitulado de "Matemática Aplicada às Ciências Agrárias", aborda os conteúdos de Função, Derivada, Integral, Função de duas variáveis, Geometria Analítica e Álgebra Linear. O objetivo desse livro é "apresentar uma Matemática mais próxima da realidade, estimulando a interdisciplinaridade, essencial a um aprendizado eficiente, bem como, novas perspectivas de trabalho e pesquisa para os futuros profissionais das Ciências Agrárias (SVIERCOSKI, 2008, p.19)". Este material apresenta excelentes modelos de aplicações, mas, alguns contextos já estão desatualizados.

O segundo livro é uma publicação do International Plant Nutrition Institute - EUA, 2012, traduzido, em 2015 pela Escola Superior de Agricultura Luiz de Queroz - Piracicaba-SP (ESALQ-USP-SP), intitulado de "Matemática e Cálculos para Agrônomos e Cientistas do Solo", este livro tem por objetivo ensinar os gestores de recursos naturais e futuros a integrar informações de diferentes disciplinas e executar cenários de gestão inovadora, usando a melhor ciência disponível." (CLAY, et al, 2015, p. IX). Este material apresenta a integração de diversos conceitos básicos de Matemática e da Estatística com assuntos da Agronomia, em especial, a subárea de solos.

Mitchel (2012) publicou a segunda edição revisada do livro 'Mathematical applications in Agriculture", o livro, em idioma inglês, traz diversas aplicações de conteúdos matemáticos na produção agrícola, na horticultura, produção de gado, Agronegócio e gestão financeira. Os objetivos deste livro são: “dar ao aluno uma base sólida em aplicações matemáticas práticas na agricultura e oportunidade de desenvolver suas habilidades de pensamento, por meio dos problemas desenvolvidos com fatos agrícolas reais; (MITCHEL, 2012, p. x)". O livro em questão se destaca por apresentar as aplicações de maneira atualizada, levando em conta os preços praticados pela indústria, medicamentos e produtos químicos tratados de acordo com a adminstração vigente no USA. Outro ponto importante é a apresentação no decorrer dos capítulos de figuras ilustrativas adicionais, para ajudar os estudantes e instrutores a visualizar o equipamento que está sendo usado na operação de hoje, de acordo com as novas práticas agrícolas.

O quarto livro encontrado intitulado de "Mathematics for Agriculture" de Rogers (2000), em idioma inglês, apresenta os conteúdos de operações, frações, decimais, porcentagens, gráficos, introdução à álgebra, equações lineares, razão e proporção, fórmulas especiais e medições. O principal objetivo deste livro é fornecer uma revisão relevante em agricultura da aritmética básica, interpretação estatística e conceitos de álgebra. $O$ autor relata que "os problemas de aplicações utilizam situações atuais, nativas e realistas, semelhantes às encontradas pelos profissionais envolvidos na agricultura de produção, na criação de culturas e na pecuária, e por pessoas empregadas em ocupações e indústrias relacionadas com agricultura (ROGERS, 2000, p. v.)". Este livro é diferente dos outros dois internacionais já apresentados. Em sua estrutura traz as chamadas de capítulos com o nome do conteúdo matemático e não com o tema de aplicação, como aparecem em Clay, et al (2015) e Mitchel (2012).

E por fim, o mais recente material publicado foi um e-book intitulado "Matemática aplicada ao ensino de ciências agrárias", a obra é o resultado de uma experiência docente ao ministrar a disciplina de Matemática Aplicada, no curso Técnico em Agropecuária, da modalidade subsequente, no Instituto Federal do Espírito Santo, campus Itapina. Para o autor, a ideia do livro surgiu porque "havia uma grande dificuldade por parte dos alunos para associar os conhecimentos matemáticos nas disciplinas do núcleo técnico" (MAGELA, 2018, p. 9). A obra é composta por oito capítulos com os seguintes conteúdos: Unidades de medida, Geoemetria, Trigonometria, Cálculo álgébrico, Equações, Matemática financeira, Funções e Estatística. Este material inclusive é bem completo em relação às aplicações e possui a maioria dos conteúdos citados pelos profesores na presente pesquisa.

Os livros citados trazem diversas aplicações no contexto das Ciências Agrárias, três deles, Sviercoski (2008), Clay, et al (2015) e Magela (2018) trazem aplicações com foco aos cursos de Agronomia e Técnicos em Agropecuária . Mitchel (2012) e Rogers (2000) também apresentam maior destaque à área da agricultura, mas, apresentam 
aplicações na criação de gado e na gestão financeira da pecuária, objetos de estudo da Zootecnia. Nenhum dos livros cita aplicações direcionadas a Engenharia Florestal.

Com relação as publicações que abordam o ensino e aprendizagem de Matemática na área de Ciências Agrárias, constatou-se que, até então, pouca exploração em pesquisas, dentre elas, Rodrigues (2006), que compartilhou uma proposta de recursos e estratégias para aulas de Matemática em cursos de Ciências Agrárias. O objetivo do trabalho foi:

[...] criar uma seção transversal para ser desenvolvida durante o transcorrer de uma disciplina. Buscando alguns modelos matemáticos ou aplicações concretas da matemática, objetivando propiciar uma motivação maior ao aluno, e desta forma desenvolver um tema, um problema ou um assunto de modo mais abrangente a partir das aulas de Matemática. (RODRIGUES, 2006, p.75).

Para o autor, o uso de aplicações se torna relevante e enriquecedor para os estudantes, pois, no contexto das Ciências Agrárias é essencial "incentivar seus alunos a lerem e vivenciarem aplicações da Matemática por profissionais da área em que estão estudando". (RODRIGUES, 2006, p.75).

Também se faz pertinente citar um trabalho realizado na escola Agrotécnica Federal de Catu (BA), que objetivou refletir sobre o uso da História da Matemática na aprendizagem e contextualização da Matemática do futuro técnico em agropecuária. $O$ trabalho foi desenvolvido através do método de resolução de problemas com o conteúdo de Geometria Espacial. Para a autora, a proposta serviu como elemento motivador acerca do uso da Matemática e forneceu elementos que incentivam práticas pedagógicas centradas no aluno (SOUZA, 2009). Embora a ação não tenha sido realizada no Ensino Superior, se aproxima da presente pesquisa em características voltadas à contextualização.

Outra publicação é um artigo apresentado em um evento, no ano de 2015. Ao apresentar as possíveis aproximações entre o ensino de Matemática e o contexto das Ciências Agrárias com aporte à interdisciplinaridade, Pereira e Santos Junior (2015) indicam que as aproximações interdisciplinares podem mostrar como o saber matemático contribui para o ensino na área de Ciências Agrárias. "A percepção da ampla aplicação que a Matemática possui se constitui em uma nova metodologia para despertar o interesse dos estudantes". (PEREIRA; SANTOS JUNIOR, 2015, p.7).

Pereira e Santos Junior (2019) também compartilharam uma experiência de ensino de funções matemáticas na área Ciências Agrárias, por meio de uma prática contextualizada em sala de aula, nos cursos de Agronomia e Zootecnia. Para os autores, "com esta experiência de ensino, foi possível garantir uma aprendizagem de funções contextualizada, utilizando exemplos atualizados e científicos da área. [...] e beneficiou o professor pesquisador em suas descobertas de novos contextos deste conteúdo.(PEREIRA e SANTOS JUNIOR, 2019, p.45)"

Neste sentido, o que há na literatura sobre a integração de Matemática e as Ciências Agrárias apontam para um trabalho interdisciplinar, que desperta para o "aprender a intervir sem destruir o construído" (FAZENDA, 2011. p. 28). Ou seja, quando há uma atitude de promover aprendizagem com significados, utilizando a contextualização é necessário que os contextos façam sentidos reais e não sejam suposições deslocadas da realidade.

O desenvolvimento das competências necessárias requer a conjugação de diferentes saberes disciplinares sejam de ordem prática e/ou didática. Entenda-se por saberes disciplinares: saberes da experiência, saberes técnicos e saberes teóricos interagindo dinamicamente. (FAZENDA, 2014). Para Ocampo, Santos e Folmer (2016) o desejo 
em contextualizar no ensino mostra a preocupação dos docentes com a formação cidadã dos alunos e conduz para que estes possam atuar de forma mais impactante na sociedade.

\section{Resultados e discussões}

A interação entre as diversas disciplinas de um currículo é uma estratégia para promover uma aprendizagem com significados. Para Baldoíno (2012), alcançar a tão almejada "aprendizagem com significado" no contexto universitário, exige do professor habilidades de comunicação. A forma de apresentar o objeto de ensino precisa estar munida de "sedução pedagógica". Logo, acredita-se que a contextualização no ensino é a chave para comunicar de maneira sedutora conteúdos matemáticos, exemplificando aplicações na área de profissionalização do estudante.

Machado (2005) aponta que se busca com a interdisciplinaridade uma intercomunicação efetiva entre as disciplinas, por meio do enriquecimento das relações entre elas. O objetivo desta ação é a composição de um objeto comum, por meio dos objetos particulares de cada uma das disciplinas componentes. Há, portanto, nas unidades disciplinares a manutenção dos métodos em referência aos objetos, na qual a horizontalidade é característica básica das relações estabelecidas.

Conforme já explicitado, as acategorias apresentam o rol de disciplinas profissionalizantes que utilizam Matemática, os conteúdos matemáticos que podem ser contextualizados na área Ciências Agrárias e os assuntos citados pelos professores que subsidiaram a busca de contextos. Diante disso, na sequência serão apresentados e analisados os dados de cada categoria.

\subsection{Categoria "disciplinas profissionalizantes que utilizam matemática}

A categoria "Disciplinas profissionalizantes que utilizam Matemática" mapeia as disciplinas que os estudantes dos cursos, segundo os docentes pesquisados, podem fazer uso de conceitos de Matemática. Dos 80 (oitenta) professores que responderam ao questionário, 12 (15\%) responderam que não utilizam conceitos matemáticos em sua disciplina e 68 (85\%) responderam que utilizam. No Quadro 1, a seguir, estão elencadas as disciplinas profissionalizantes da área Ciências Agrárias que utilizam conceitos de Matemática. A organização foi realizada por curso.

\section{Quadro 1}

Disciplinas profissionalizantes da área Ciências Agrárias que utilizam conceitos de Matemática

\begin{tabular}{|l|l|}
\hline \multicolumn{1}{|c|}{ Curso } & \multicolumn{1}{c|}{ Disciplinas } \\
\hline & Floricultura e Paisagismo; Silvicultura; Desenho Técnico; Genética; \\
& Fitopatologia I; Hidráulica e Irrigação; Hidrologia e Drenagem; Topografia \\
& II; Microbiologia Geral; Microbiologia e Biologia do solo; Ecologia Geral; \\
& Experimentação Agrícola; Morfogênese e Física do solo; Manejo de Bacias \\
& hidrográficas; Forragicultura; Fertilidade do solo; Administração rural; \\
& Administração e planejamento de propriedades; Construções Rurais; \\
& Máquinas e Mecanização; Bovinocultura de corte e de leite; Recursos \\
genéticos e melhoramento vegetal; Culturas I; Culturas II, Ecofisiologia e & Manejo da Soja; Cooperativismo e comercialização agrícola; Projetos, \\
& avaliações e perícias; Avicultura; Suinocultura; Entomologia; Controle \\
& Biológico; Anatomia Vegetal; Topografia I; Fruticultura Básica; \\
& Fruticultura aplicada; Pós-colheita de produtos Hortícolas; Olericultura; \\
& Plantas medicinais; Tópicos especiais em agronomia; Agrometereologia e \\
& climatologia; Agroecologia; Mapeamento de Agricultura de Precisão; \\
& Classificação de solos; Gênese e morfologia do solo; Sistemas \\
\hline
\end{tabular}




\begin{tabular}{|c|c|}
\hline & $\begin{array}{l}\text { agrosilvipastoris; Tratos e métodos silviculturais; Manejo e conservação } \\
\text { do solo. }\end{array}$ \\
\hline Engenharia Florestal & $\begin{array}{l}\text { Sementes, mudas e viveiros Florestais; Silvicultura; Ecologia Urbana; } \\
\text { Parques e Jardins; Inventário Florestal; Fitossociologia; Desenho Técnico; } \\
\text { Incêndios Florestais; Perícias e avaliações de impactos ambientais; } \\
\text { Melhoramento Genético de espécies florestais; Fitopatologia I; Hidráulica } \\
\text { e Irrigação; Hidrologia e Drenagem; Ajustamento de observações } \\
\text { geodésicas; Fotogrametria e Fotointerpretação; Fitopatologia aplicada; } \\
\text { Fertilidade do solo; Recursos Energéticos; Experimentação; Morfogênese } \\
\text { e Física do solo; Manejo de Bacias hidrográficas; Topografia e elementos } \\
\text { de geodésica; Métodos e medidas de posicionamento; Tecnologia da } \\
\text { Madeira II; Biometria Florestal; Manejo Florestal; Crescimento e } \\
\text { produção florestal; Introdução à ciência do solo; Entomologia Florestal; } \\
\text { Controle Biológico; Agroclimatologia; Agroecologia; Recursos florestais; } \\
\text { Sistemas agrosilvipastoris; Manejo e conservação do solo. }\end{array}$ \\
\hline Zootecnia & $\begin{array}{l}\text { Análise de alimentos; Forragem 1; Plantas Forrageiras; Fertilidade do } \\
\text { solo; Administração rural; Planejamento de propriedades; Desenho e } \\
\text { construções rurais; Máquinas e mecanização; Avaliação animal; Tópicos } \\
\text { especiais em ruminantes; Biologia molecular; Culturas de interesse } \\
\text { zootécnico; Gestão econômica aplicada à Zootecnia; Mercados } \\
\text { Agropecuários; Alimentação de não-ruminantes; Avicultura; Suinocultura; } \\
\text { Topografia; Nutrição de animais de companhia; Bioclimatologia animal; } \\
\text { Criações alternativas; Forragem 2, Fisiologia Vegetal; Melhoramento } \\
\text { genético animal II; Apicultura; Bovinocultura de leite; Anatomia animal; } \\
\text { Ovicocultura e Caprinocultura; Genética animal; Melhoramento animal I; } \\
\text { Nutrição animal; Fisiologia animal; Aquicultura; Bubalinocultura; } \\
\text { Farmacologia; Climatologia; Agroecologia; Sistemas agrosilvipastoris; } \\
\text { Manejo e conservação do solo. }\end{array}$ \\
\hline
\end{tabular}

Fonte: Autores, 2021.

Ao analisar esta categoria, foi possível observar que dos professores pesquisados que utilizam conceitos de Matemática, 5 (cinco) atuam nos três cursos, (Agronomia, Engenharia Florestal e Zootecnia), 10 (dez) professores atuam apenas no curso de Agronomia, 11 (onze) apenas na Engenharia Florestal, 16 (dezesseis) professores atuam apenas no curso de Zootecnia, 2 (dois) professores atuam simultaneamente nos cursos de Engenharia Florestal e Zootecnia, 13 (treze) professores atuam simultaneamente nos cursos de Agronomia e Zootecnia e por fim, 16 (dezesseis) professores atuam simultaneamente nos cursos de Agronomia e Engenharia Florestal.

Estas informações mostram que além das disciplinas básicas como Matemática, Física, Química, Biologia, entre outras, diversas disciplinas profissionalizantes são comuns entre os cursos. Este fato é motivador para a transposição didática no ensino de Matemática, que pode ter exemplos de contextos que são aplicados aos três cursos, formando assim, uma rede de interação do conhecimento. Nesse sentido, a interação é "condição de efetivação da interdisciplinaridade. Pressupõe uma integração de conhecimentos visando novos questionamentos, novas buscas, enfim, a transformação da própria realidade”. (FAZENDA, 2011, p.12).

Diante do exposto nesta subcategoria, é possível destacar que o campo de aplicações da Matemática na área Ciências Agrárias é bem amplo e que o trabalho interdisciplinar se torna necessário, pois, a interdisciplinaridade consiste na "interação das disciplinas científicas, de seus conceitos, diretrizes, de sua metodologia, de seus procedimentos, de seus dados e da organização de seu ensino". (FAZENDA, 2011, p.35).

Os dados levantados descrevem resultados referentes a um estudo de caso de uma instituição. Logo, outros cursos da área Ciências Agrárias de outras instituições podem ter disciplinas diferentes, bem como, as aplicações 
de Matemática podem aparecer ou não em cada disciplina, de acordo com a postura pedagógica adotada pelo professor.

Contudo, a busca por um ensino interdisciplinar é uma atitude que deve partir do professor pesquisador em diálogo com outros professores de diversas disciplinas. A busca de contextos e a integração da Matemática com tais contextos podem ser uma metodologia motivadora no ensino, capaz de promover a valorização da disciplina de Matemática nos currículos dos cursos da área Ciências Agrárias.

\subsection{Categoria "Conteúdos matemáticos"}

Na categoria "Conteúdos Matemáticos", organizou-se uma tabela (Tabela 1) que contempla a quantidade de citações pelos professores pesquisados e os respectivos conteúdos. Além disso, esta categoria justifica a importância das disciplinas de Matemática nos currículos dos cursos da área Ciências Agrárias.

Tabela 1

Frequência de citações dos conteúdos matemáticos nos relatos dos professores pesquisados

\begin{tabular}{|c|c|}
\hline Conteúdos/palavras & Quantidade de Citações \\
\hline Regra de Três & 28 \\
\hline Cálculo de Área & 15 \\
\hline Equações & 14 \\
\hline Matemática Básica & 11 \\
\hline Cálculo de Volume & 10 \\
\hline Porcentagem; Unidades de Medidas & 9 \\
\hline Proporção; Custos & 7 \\
\hline Média; Matriz; Funções; Trigonometria & 5 \\
\hline Escala; Probabilidade; Estatística & 4 \\
\hline $\begin{array}{l}\text { Álgebra; Receita; Financeira; Modelagem; Variância; Operações } \\
\text { Básicas }\end{array}$ & 3 \\
\hline $\begin{array}{l}\text { Juros; Taxa; Integral; Amostragem; Geometria; Curvas; Desvio } \\
\text { Padrão; Logaritmos }\end{array}$ & 2 \\
\hline Derivada, Regressão; Potência; Frações; Moda; Mediana & 1 \\
\hline
\end{tabular}

Fonte: Autores, 2021.

O conteúdo matemático com maior número de citações foi Regra de Três. Este algoritmo matemático baseado na razão e na proporção entre grandezas foi citado como frequentemente utilizado nos três cursos. Os discursos dos professores PT16, PT06, PT53 e PT01, das disciplinas de Bovinocultura de Leite (Zootecnia), Fitossociologia (Engenharia Florestal), Culturas I e II (Agronomia) e Manejo e Conservação do Solo (disciplina dos três cursos), respectivamente, apresentam alguns contextos nos quais o algoritmo de Regra de Três é aplicado:

Cálculo de ração e evolução de rebanho. Desde uma simples Regra de Três até um sistema de equações. (PT16)

Fitossociologia - Regra de Três para extrapolação de área. (PT06)

Regra de Três na regulagem de pulverizadores; Determinação de taxas de adubação; formulação de adubos; Porcentagem; Densidade x arranjo de plantas; Determinação 
de componentes de rendimento; Regulagem de semeadora; ajustes para colheita. (PT53)

Dinâmica da Matéria orgânica, Equação de perdas de solo e água, Física do solo. Em todos se utiliza conceitos relativos de Regra de três e porcentagem. (PT01). (DADOS DA PESQUISA, 2016).

As declarações dos professores tornam possível apontar que a Regra de Três é um conteúdo matemático significativo para a formação de profissionais da área Ciências Agrárias e convidativo para uma abordagem interdisciplinar no ensino de Matemática.

Ainda nesse contexto, na Tabela 1 é possível observar que foram citados os conteúdos de Porcentagem (9 citações) e Proporção (7 citações). O cálculo de porcentagem é utilizado nos mais variados contextos, como por exemplo, representar situações na forma de taxa ou proporção, e se configura uma extensão do conteúdo de Regra de Três. Nesta pesquisa, foi citado como conteúdo de Matemática utilizado na "Bubalinocultura - nutrição animal, (cálculo de ração, exigências de nutrientes)", (PT43) na "Determinação de taxas de adubação; formulação de adubos" (PT46), entre outros.

Já o conteúdo de Proporção, integrado a conteúdos já apresentados, (Regra de Três e Porcentagem) foi citado pelos professores das disciplinas de Ecologia, Recursos Genéticos, Recursos Energéticos Florestais, Biodegradação e Preservação, Componentes Químicos e Anatômicos, Anatomia e Fisiologia animal e Fertilidade do Solo. Também uma aplicação de Regra de Três, conhecida como escala foi descrita como usual nas disciplinas de Topografia, (disciplina dos três cursos), Construções Rurais, Mapeamento de Agricultura de Precisão e Floricultura e Paisagismo.

Logo, os conteúdos de Proporção, Regra de Três e Porcentagem precisam ser trabalhados nas disciplinas de Matemática nos cursos da área Ciências Agrárias, pois, é necessária uma abordagem interdisciplinar que relacione método, fenômeno em estudo e uma relação dinâmica entre as diferentes disciplinas e a realidade (FAZENDA, 2011). Sendo assim, estes conteúdos além de se mostrarem úteis pela quantidade de contextos abrangentes, possibilitam a prática docente interdisciplinar com diversidade de aplicações, facilitando a transposição didática.

Na sequência, o segundo conteúdo mais citado foi área, conceito de uso comum no contexto das Ciências Agrárias. O seu cálculo pode ser manual, utilizando funções trigonométricas, fórmulas básicas de área e cálculo de Integral, ou ainda usando dados de Global Positioning System (GPS), em programas computacionais. Destacase, como exemplo, a aplicação do conceito de área no contexto das Ciências Agrárias, citado pelo professor da disciplina de Agricultura de Precisão do curso de Agronomia (PT29): "Mapeamento de agricultura de precisão cálculo de área, transformação de unidades $\left(\mathrm{m}^{2}\right.$-hectare- $\left.\mathrm{km}^{2}\right)$, escala, área mínima mapeável". Também no curso de Engenharia Florestal na disciplina de Silvicultura Urbana: "Escalas, cálculo de área, regras de três, cálculo financeiro, trigonometria". (PT03). E no curso de Zootecnia na disciplina de Bioclimatologia Animal, "cálculo de área, (tamanho da propriedade, galpão), custos (instalação, produção)", conforme discurso do professor PT61.

O estudo de equações também se apresentou significativo para diversos professores que mencionaram utilizar esse conteúdo matemático (14 citações). As equações podem aparecer nas mais diversas modalidades. A equação de 1 o grau foi evidenciada pelo professor PT18, que ministra a disciplina de Produtos florestais não maderáveis, no curso de Engenharia Florestal: "Equação de 10 grau; custos e receitas; Juros simples e composto". Já a equação de 2 o grau foi citada pelo professor PT44 da disciplina de Fertilidade do solo: "álgebra, (Cálculos de adubação, Proporção, Regra de Três, Porcentagem); Equações de 1ㅇ e 2o grau". O professor PT53 da disciplina de Experimentação Agrícola admitiu utilizar equações polinomiais conforme relato: "uso de conceitos como, 
Média, Variâncias, Desvio Padrão, Funções, Equações Polinomiais, Regra de Três, etc..." Também o uso de sistemas de equações foi citado pelos professores das disciplinas de Bovinocultura de leite e da Nutrição animal.

A palavra Matemática Básica apareceu diversas vezes nos relatos dos professores, é possível que os professores, por não lembrarem os nomes dos conteúdos matemáticos, explanaram dessa forma: "Cálculos básicos de soma de bases, maturação de base e de alumínio; na física do solo tem cálculo de volume de cilindro e mais aplicações de Matemática Básica em grande parte da disciplina". (PT35). Mas, há menções mais pontuais nos discursos como frações, potências, logaritmos e operações básicas.

O cálculo de volume, assim como o cálculo de área é comum no contexto das Ciências Agrárias. Nas respostas dos professores foi possível encontrar citações de cálculo de volume nas disciplinas de Sementes e Mudas Florestais, Sistemas Agrosilvipastoris, Inventário Florestal, Olericultura, Física do solo entre outras.

O conteúdo de Unidades de Medida foi citado nas disciplinas de Topografia, Construções Rurais, Química, Nutrição animal, Mapeamento de Agricultura de Precisão entre outras. Nesse contexto, o conteúdo de Unidades de Medida pode ser considerado um objeto interdisciplinar, pois, mesmo que não citado por todos os professores que utilizam Matemática, é possível encontrar referências ao uso desses conceitos, por exemplo, no discurso do professor PT26 da disciplina de Fitopatologia, (disciplina dos cursos de Agronomia e Engenharia Florestal), "Determinação de severidade e incidência de doenças; Concentração de produtos/aplicação - ex: 1 $\mathrm{ml} / \mathrm{kg}$ - $120 \mathrm{~kg} / \mathrm{ha} ; \mathrm{ppm}$ (muita dificuldade) Ex: concentração de 50 ppm". Nota-se que não foi citado o conteúdo, mas, há presença de simbologia que faz referência ao uso desse conteúdo.

A Matemática Financeira e também alguns de seus elementos como o Custo, a Receita e o cálculo de Taxas e Juros, foram citados pelos professores. São cálculos de análise de custos e receitas, na disciplina de Sistemas Agrosilvipastoris, custo e viabilidade econômica na disciplina de Aditivos na alimentação de aves e suínos, "Cálculo de rentabilidade/lucratividade em atividades (receitas/despesas etc); Análise de viabilidade econômica (matemática financeira, juros, técnicas modernas TIR-taxa interna de retorno, VL e recursos B/C Benefício/custo, VPL- Valor Presente Líquido". (PT20) na disciplina de Administração e Planejamento Rural, enfim, mesmo que muitos professores não tenham citado, é notório que esse assunto move diversos estudos de análise econômica na área Ciências Agrárias.

Corroborando com Clay et al. (2015, p.9) é preciso "ensinar os alunos a propor, testar e implementar as estratégias inovadoras que estão melhor posicionadas, para aumentar a lucratividade e a produtividade e proteger o ambiente", pois, em todas as culturas, em toda criação de animais, em todo planejamento florestal, a análise financeira é o grande responsável pelo sucesso ou insucesso das atividades.

Ainda nesta categoria, os conteúdos de Estatística também foram mencionados, como Média, Moda, Mediana, Desvio Padrão, Variâncias e Amostragem, como cita o professor PT63 da disciplina de Geoprocessamento e Sensoriamento Remoto do curso de Engenharia Florestal: "Fotogrametria - plano de voo, cálculo de abertura angular. Ajustamento - Estatística Básica, (média, desvio padrão de câmeras, moda, mediana)". Ainda neste contexto, o professor PT60 da disciplina de Experimentação Agrícola, do curso de Agronomia, descreveu o "uso de conceitos como, Média, Variâncias, Desvio Padrão, Funções, Equações Polinomiais, Regra de Três, etc..." Além disso, houve citações do uso de conteúdos de Estatística nas disciplinas de Sementes, Mudas e Viveiros Florestais, Ecologia Geral; Recursos Genéticos e Melhoramento Vegetal; Inventário Florestal e Melhoramento Animal.

A Probabilidade apareceu como conteúdo usual nos discursos dos professores das disciplinas de Genética, Experimentação Animal, Recursos Genéticos e Melhoramento Vegetal. Já o conteúdo de Matrizes é aplicado, segundo os professores, nas disciplinas de Biometria Florestal, Manejo Florestal, Nutrição de animais de companhia, Geoprocessamento e Sensoriamento remoto e Melhoramento Animal. 
O estudo de geometria foi citado, conforme resposta do professor PT07 da disciplina de Biometria Florestal: "Trigonometria, Geometria Plana, Geometria Analítica, Matrizes, Modelagem, Regressão, Integral, Regra de Três, Operações Matemáticas". Já o estudo de Trigonometria, além de ser citado no discurso do professor PT07, também foi citado pelos professores das disciplinas de Topografia e Silvicultura Urbana.

As Funções foram citadas em 5 (cinco) disciplinas: Inventário Florestal; Química Analítica; Aquicultura; Experimentação Animal e Experimentação agrícola. Esse conteúdo é utilizado também na área de Ciências Agrárias como referência de modelagem, citado pelos professores de Biometria Florestal, Aquicultura e Ovinocultura/Caprinocultura. Sviercoski (2008, p.19), acredita que os estudantes "certamente se confrontarão com a necessidade crescente de formulações quantitativas e modelos". O estudo de curvas aparece citado como usual nas disciplinas de Bioquímica e Topografia. Desse modo, por meio de modelos matemáticos clássicos de Ciências Agrárias, e a construção de modelos simplificados é possível promover motivação às aulas de Matemática (RODRIGUES, 2006).

E por fim, os conteúdos de Cálculo Diferencial e Integral, (derivada e Integral) também foram mencionados. Esses conteúdos foram referenciados pelos professores das disciplinas de Inventário Florestal e Biometria Florestal.

Os conteúdos matemáticos citados nessa categoria reforçam a importância da base matemática para a formação de um bom profissional e ainda, favorecem uma atitude interdisciplinar que busca recuperar o homem do seu pensar fragmentado e ainda destaca a ação interdisciplinar como "intervenção educativa inovadora". (FAZENDA, 2014, p.11). Sendo assim, conclui-se, que os conteúdos mais utilizados pelos professores são de Matemática Básica, com destaque aos conteúdos de Razão e Proporção, (incluindo Regra de Três e Porcentagem), Equações, Grandezas e Medidas (Área, Volume e Unidade de Medida).

É possível também refletir com relação aos conteúdos que fazem parte das ementas dos cursos pesquisados. Há muitos conteúdos que estão nas ementas que não foram citados, porém, o que preocupa é a quantidade de conteúdos que não estão nas ementas e que foram citados diversas vezes. Diante disso, para facilitar a comparação curricular, abaixo são apresentadas as ementas das disciplinas da área de Matemática, nos respectivos cursos em questão.

No curso de Agronomia são ofertadas duas disciplinas: Álgebra Linear (10 período): "Matrizes e Sistemas Lineares. Espaços Vetoriais. Transformações Lineares. Produto Interno. Autovalores e Autovetores" (UTFPR, 2015, p.60) e Cálculo A (2 período): "Funções. Limites. Continuidade. Derivadas. Diferencial. Equações Diferenciais Lineares Ordinárias de Primeira e de Segunda Ordem. Integral Indefinida. Integral Definida”. (UTFPR, 2015, p.69).

No curso de Engenharia Florestal, também são ofertadas duas disciplinas: Matemática A (10 período): “Matrizes. Determinantes. Sistemas Lineares. Espaços vetoriais. Transformações Lineares. Autovalores e Autovetores. Produto Interno" (UTFPR, 2008, p.42) e Cálculo A (2o período): “Funções. Limites. Continuidade. Derivadas. Diferencial. Equações Diferenciais Lineares Ordinárias de Primeira e de Segunda Ordem. Integral Indefinida. Integral Definida". (UTFPR, 2008, p.42).

E por fim, no curso de Zootecnia é ofertada apenas uma disciplina: Matemática (10 período): “Razão e proporção. Juros simples e compostos. Taxas equivalentes. Funções de uma variável real. Limites. Continuidade. Derivadas. Integral Indefinida e Integral Definida". (UTFPR, 2012, p.38).

Essa comparação das ementas das disciplinas com os conteúdos citados no questionário da pesquisa, aponta para um questionamento sobre os currículos dos cursos no Ensino Superior na área Ciências Agrárias. Aos graduandos é ofertado um currículo de Matemática robusto, dito em um nível elevado, sendo que o básico, muitas vezes, não dominados pelos alunos é deixado de lado, como se fosse uma obrigação dos estudantes já 
ter esse domínio básico dos conteúdos de Matemática. Mas, é possível refletir que, nas graduações estão alunos reféns de um sistema educacional que os aprovou em diversas séries escolares sem ter obtido a aprendizagem.

\subsection{Categoria "Assuntos contextualizados"}

Nesta categoria, será contemplada, segundo os dados do questionário aplicado aos professores das áreas técnicas, à quantidade de citações dos assuntos que relacionam a Matemática ao conteúdo da disciplina. A Tabela 2 apresenta a frequência destas citações.

Tabela 2

Frequência de citações dos assuntos/palavras nos relatos dos professores pesquisados

\begin{tabular}{lc}
\hline Palavra/Assunto & Quantidade de citações \\
\hline Cálculo & 59 \\
\hline Solos & 19 \\
\hline Animal & 15 \\
\hline Ração & 15 \\
\hline Adubação & 12 \\
\hline Plantas & 10 \\
\hline Densidade & 8 \\
\hline Sementes & 7 \\
\hline Ambientais & 4 \\
\hline Dimensionamento & 4 \\
\hline Dosagem & 4 \\
\hline
\end{tabular}

Na Tabela 2 mencionada, observa-se que a palavra cálculo teve o maior número de citação nos discursos, foi comum os professores referenciarem desta forma para exemplificar que utilizam Matemática. É o que mostra a resposta do professor PT43: "Cálculo de adubação. Densidade semeadura (cálculos) de plantas de cobertura de inverno. Cálculo de dosagens de aplicações de fungicidas e inseticidas. Cálculo de dosagem de reguladores de crescimento". Observe que não foi citado o conteúdo matemático, mas, deixado claro para que utiliza os cálculos no contexto da disciplina.

O estudo de solos foi citado constantemente, principalmente por professores do curso de Agronomia e da Engenharia Florestal. Abaixo estão alguns dos discursos que aparecem esse assunto:

Interpretação de análise de solos e recomendação de adubos e corretivos. (PT14)

Correção da fertilidade de solo. Dimensionamento de canteiros e bancadas em cada vegetação. (PT28)

Cálculo da estimativa das características químicas do solo (CTC, V\%, M\%, SB). Propriedades físicas - cálculo de densidade (volume do cilindro) do solo, porosidade. (PT40). (DADOS DA PESQUISA, 2016). 
Diante desses discursos fica evidente que o contexto da subárea de Solos pode e deve ser utilizado numa perspectiva interdisciplinar com disciplinas da área de Matemática. Juntamente com esse contexto é possível agregar outros assuntos citados como adubação, plantas e sementes.

O assunto ração, (cálculo, formulação e fornecimento) também foi bastante citado. O cálculo de ração é um assunto da área de Zootecnia, interligado com a criação animal, (citado 15 vezes). O cálculo de ração foi citado como assunto de aplicação da Matemática nas disciplinas de Bovinocultura de Corte; Nutrição de Animais de Companhia; Ovinocultura e Caprinocultura; Aquicultura; Bubalinocultura; Avicultura; Suinocultura; Alimentação de Não-Ruminantes; Nutrição Animal e Bovinocultura de Leite. Todas as disciplinas descritas são específicas da área de formação profissional da Zootecnia e também disciplinas de formação complementar da Agronomia

Sendo assim, aqui tem-se um assunto com potencial multidisciplinar no contexto destes dois cursos, para Fazenda (2011, p.70) esse nível de multidisciplinaridade é uma "atitude de justaposição de conteúdos de disciplinas heterogêneas ou a integração de conteúdos numa mesma disciplina, atingindo-se, quando muito, o nível de integração de métodos, teorias ou conhecimentos".

O conceito de densidade também foi declarado usual na área de Ciências Agrárias. A expressão que relaciona a massa de um material e o volume por ele ocupado foi citada nas disciplinas de Aquicultura; Culturas I e II, Gênese e Morfologia do Solo; Sementes, Mudas e Viveiros Florestais; Construções Rurais; Fruticultura; Química Geral e Geologia e Pedologia. O cálculo de densidade pode ser utilizado como um exemplo contextualizado do conteúdo de Razão e Proporção, para os três cursos pesquisados.

A palavra "ambientais" foi destacada nesse estudo por trazer contextos significativos do curso de Engenharia Florestal, como mostra o discurso do professor PT10, "Avaliação de grau de perigo de incêndios florestais; Avaliação de área de reserva legal e de preservação permanente; Avaliação de impactos ambientais; Cálculo de multas ambientais". (DADOS DA PESQUISA, 2016).

O assunto dimensionamento foi mencionado em diferentes situações. Na disciplina de Construções Rurais, "dimensionamento de telhados", na Ovinocultura e Caprinocultura, "dimensionamento de Rebanho", na Floricultura e Paisagismo, "dimensionamento de canteiros" e na disciplina de Avicultura, "dimensionamento de galpão". Esse fato desperta para a construção do conhecimento baseado "nas relações estimuladas por múltiplos contextos, com diferentes características". (SPINELLI, 2011, p.13).

A palavra dosagem também foi citada pelos professores como referência de cálculos matemáticos. O discurso dos professores na sequência ilustra esse caso: "Cálculo de dosagem na farmacologia" (P34), "Cálculo de dosagens de aplicações de fungicidas e inseticidas. Cálculo de dosagem de reguladores de crescimento" (P30).

Diante do exposto, conclui-se que há uma diversidade de assuntos que podem garantir a aprendizagem por meio da integração de conceitos matemáticos e a área das Ciências Agrárias. Aqui, nesse texto foi apresentada uma amostra, de acordo com o maior número de citações, entretanto, em todos os discursos há referências de aplicações de conceitos matemáticos e que outras descobertas virão com o aprofundamento destes assuntos.

Logo, a contextualização é algo fundamental para que um profissional de Ciências Agrárias tenha uma formação dos conceitos articulados, proporcionando um raciocínio crítico sobre os fatos. Concorda-se com Spinelli (2011), que a contextualização é uma parte necessária da prática docente, que alicerça um trabalho efetivamente interdisciplinar, na qual a criação de contexto é o ponto de partida para a interdisciplinaridade.

Como já exposto, o trabalho interdisciplinar exige atitude do professor e aprofundamento de contextos, pois, a "atitude interdisciplinar possibilita não apenas a interação de conteúdo, mas também a interação entre pessoas, já que essa perspectiva tem potencial para motivar outros professores que compõem o corpo docente". (OCAMPO; SANTOS; FOLMER, 2016, p.1017). Nesse sentido, "no ensino de Matemática, novas fontes de 
conhecimento são geradas, no diálogo com contextos de suas aplicações, criando assim, uma rede de significados para os conceitos ditos abstratos e sem utilidade". (PEREIRA; SANTOS JUNIOR, 2015, p.7).

Nesse sentido, cabe considerar que o estudo se caracterizou como uma das etapas na busca por um ensino de Matemática interdisciplinar e, com a aplicação do questionário foi possível mapear conteúdos matemáticos e contextos de aplicabilidade da Matemática na área Ciências Agrárias.

Constatou-se que conteúdos de Matemática Básica como Regra de Três, Porcentagem, Equações, Unidades de Medidas, Cálculos de Área, Volume, entre outros, se destacam nos registros dos professores nos questionários e, que conteúdos ditos do Ensino Superior foram poucas vezes citados e para alguns nem se fez menção.

Não se pode concluir que alguns conteúdos das ementas das disciplinas de Matemática dos cursos pesquisados não sejam aplicáveis, visto que muitos professores citaram apenas assuntos das disciplinas ou somente as disciplinas que utilizam o conhecimento matemático. Todavia, é possível afirmar que há conteúdos que deveriam estar no currículo dos cursos, devido a sua alta aplicabilidade, é o caso da Razão, Proporção e Regra de Três, presente apenas no currículo do curso de Zootecnia, porém, com inúmeras aplicações na Agronomia e na Engenharia Florestal.

Outro dado importante, levantado por esta pesquisa são as disciplinas comuns aos três cursos pesquisados, como é o caso de Manejo e Conservação do solo, Topografia e Agroecologia. Além disso, disciplinas do curso de Agronomia são complementares para o curso de Zootecnia e vice-versa, o mesmo acontece com a Engenharia Florestal e o curso de Agronomia. Esse fato aponta para uma abordagem multidisciplinar, com o objetivo de trazer significados para um assunto com diversas aplicações.

\section{Considerações finais}

Esta pesquisa contribuiu para a ampliação do diálogo entre a Matemática e a área Ciências Agrárias, além de ser um início da promoção à interdisciplinaridade. Os professores das áreas técnicas elencaram conteúdos matemáticos e assuntos das disciplinas que usam Matemática, mas, também tiveram o cuidado de alertar quais conteúdos os acadêmicos têm mais dificuldade ou quais são mais importantes. Este fato reforça a importância da interdisciplinaridade no diálogo entre às áreas.

Este estudo caracterizou-se como uma das etapas na busca por um ensino de Matemática interdisciplinar na área das Ciências Agrárias. Com a aplicação do questionário foi possível mapear conteúdos matemáticos e contextos de aplicabilidade da Matemática na área de Ciências Agrárias.

Constatou-se que conteúdos de Matemática Básica como Regra de Três, Porcentagem, Equações, Unidades de Medidas, cálculos de área, volume, entre outros, se destacam nas aplicações e que conteúdos ditos do Ensino superior foram poucas vezes citados e para alguns nem se fez menção.

Não se pode concluir que alguns conteúdos das ementas das disciplinas de Matemática dos cursos pesquisados não sejam aplicáveis, visto que muitos professores citaram apenas assuntos das disciplinas ou somente as disciplinas que utilizam o conhecimento matemático. Todavia, é possível afirmar que há conteúdos que deveriam estar no currículo dos cursos, devido a sua alta aplicabilidade, é o caso da Razão, Proporção e Regra de Três, presente apenas no currículo do curso de Zootecnia, porém, com inúmeras aplicações na Agronomia e na Engenharia Florestal.

Outro dado importante, levantado por esta pesquisa são as disciplinas comuns aos três cursos pesquisados, como é o caso das disciplinas de Manejo e Conservação do solo, Topografia e Agroecologia. Além disso, disciplinas do curso de Agronomia são complementares para o curso de Zootecnia e vice-versa, o mesmo acontece com a 
Engenharia Florestal e o curso de Agronomia. Esse fato aponta para o planjemento de uma abordagem multidisciplinar com o objetivo de trazer significados para um assunto com diversas aplicações.

\section{Referências}

Baldoíno, E. F. (2012). Ensinar e Aprender na Educação Superior: Possibilidades de Uma Prática Progressista. Revista de Ensino, Educação e Ciências Humanas.Londrina, v. 13, n. 2, p. 25-34. Recuperado de http://www.pgsskroton.com.br/seer/index.php/ensino/article/view/685.

Bardin, L. (2016). Análise de Conteúdo. Tradução Luís Antero Reto, Augusto Pinheiro. São Paulo: Edições 70.

Clay, D. E. Carlson, C. G. Clay, S. A. Murrell, T.S. (2015). Matemática e Cálculos para Agrônomos e Cientista do Solo. Piracicaba: International Plant Nutrition Institute.

Fazenda, I. C. A. (2011). Integração e interdisciplinaridade no ensino brasileiro: Efetividade ou ideologia. 6. ed. São Paulo: Edições Loyola.

Fazenda, I. C. A. (Org).(2014). Interdisciplinaridade: pensar, pesquisar e intervir. São Paulo: Cortêz.

Magela, M. M. (2018). Matemática aplicada ao ensino de ciências agrárias. Vitória: Edifes. Recuperado de https://repositorio.ifes.edu.br/handle/123456789/813

Mitchel, N. H. (2012). Mathematical applications in agriculture. 2. ed. Boston (USA): Cengage Learning.

Ocampo, D. M. Santos, M. E. T. dos. Folmer, V. (2016). A Interdisciplinaridade no Ensino É Possível? Prós e contras na perspectiva de professores de Matemática. Bolema: Rio Claro (SP), v. 30, n. 56, p. 1014- 1030. Recuperado de http://www.scielo.br/pdf/bolema/v30n56/1980-4415-bolema-30-56-1014.pdf

Pereira, L. B. C. Santos junior, G. (2015). O Ensino de Matemática nas Ciências Agrárias: possíveis aproximações interdisciplinares. ANAIS... VII Encontro Mineiro de Educação Matemática. São João Del Rei. Recuperado de http://www.ufjf.br/emem/files/2015/10/O-ENSINO-DE-MATEMATICA-NAS-CI\%C3\%8ANCIASAGR\%C3\%81RIAS-POSS\%C3\%8DVEIS-APROXIMA\%C3\%87\%C3\%95ES-INTERDISCIPLINARES.pdf

Pereira, L. B. C. Santos junior, G. (2019). Ensino de funções nas ciências agrárias: uma prática contextualizada nos cursos de agronomia e zootecnia. Revista Práxis, v. 11, n. 21. Recuperado de http://revistas.unifoa.edu.br/index.php/praxis/article/view/1350/2425

Rodrigues, W. M. (2016). Recursos e estratégias propostas para aulas de matemática em cursos de ciências agrárias. Revista Educação Agrícola Superior. Publicação da Associação Brasileira de Educação Agrícola Superior- ABEAS.Vol. 21 № 01. Recuperado de http://www.abeas.com.br/wt/files/16_2006.1.pdf

Rogers, B. C. (2000). Mathematics for agriculture. 2. ed. New York (USA): Interstate Publishers.

Souza, J. F.(2009). Construindo uma aprendizagem significativa com história e contextualização da matemática. Dissertação (Mestrado em Educação) - Universidade Federal Rural do Rio de Janeiro, Rio de Janeiro. Recuperado de https://tede.ufrrj.br/jspui/handle/tede/131

Spinelli, W. (2011). A construção do conhecimento entre o abstrair e o contextualizar: o caso do ensino da Matemática. Tese de doutorado - Faculdade de Educação, Universidade de São Paulo, São Paulo. Recuperado de www.teses.usp.br/teses/disponiveis/48/48134/tde...134105/.../WALTER_SPINELLI.pdf

Sviercoski, R. F. (2008). Matemática Aplicada a Ciências Agrárias: análise de dados e modelos. 4ạ reimpr.Viçosa:UFV. 
UTFPR - Universidade Tecnológica Federal do Paraná. (2008). Projeto de Abertura do Curso de Engenharia Florestal. Dois Vizinhos. Recuperado de https://portal.utfpr.edu.br/cursos/coordenacoes/graduacao/doisvizinhos/dv-engenharia-florestal/documentos/outros-documentos/projeto-de-curso-engenharia-florestalutfpr-dv/view

UTFPR - Universidade Tecnológica Federal do Paraná. (2012). Projeto Pedagógico do Curso de Bacharelado em Zootecnia da UTFPR. Dois Vizinhos. Recuperado de https://portal.utfpr.edu.br/cursos/coordenacoes/graduacao/dois-vizinhos/dvzootecnia/documentos/documentos-do-curso-de-zootecnia/ppc-zootecnia-2016-com-resolucoes.pdf

UTFPR - Universidade Tecnológica Federal do Paraná. (2015). Projeto Pedagógico do Curso de Bacharelado em Agronomia da UTFPR. Dois Vizinhos. Recuperado de https://portal.utfpr.edu.br/cursos/coordenacoes/graduacao/dois-vizinhos/dvagronomia/documentos/ppc_agronomia.pdf

Esta obra está bajo una Licencia Creative Commons Attribución-NoCommercial 4.0 International

\section{(cc) BY-NG}

